\title{
Introduction: Empathy, Shared Emotions, and Social Identity
}

\author{
Thomas Szanto $^{1}$ - Joel Krueger ${ }^{2}$
}

Published online: 26 February 2019

๑) Springer Nature B.V. 2019

Our social encounters are dizzyingly complex. They not only involve overlapping layers of affective, conative, and cognitive engagements between self and others. They are also deeply embedded in continually-changing environments that shape experiential, emotional, and epistemic forms of sharing distinctive of these encounters-forms of sharing that are, in turn, further modulated by contextual factors such as real or imagined group membership and shifting social identities. Moreover, each of these social processes variously affects and feeds back onto the others. This complex tangle of multi-layered processes supports core social capacities like our capacity for interaction, cooperation, affective sharing, joint agency, and social identification. It also directly impacts our capacity for empathy: our ability to perceive, understand, and respond to the experiences and behavior of others. Empathy is facilitated-but also modulated, biased, or even disrupted by-various aspects of these processes. In other words, empathy is a robustly situated practice, one that is bound up with a rich array of processes that encompass not only the dynamics of our face-to-face engagements but also the complex environments in which these engagements develop and take shape.

To be sure, it is not controversial so say that these fundamental dimensions of our sociality, which can be broadly subsumed under the labels "empathy", "shared emotions", and "social identity", are variously and massively interconnected. Most contemporary philosophers, cognitive scientists, developmental and social psychologists, and social neuroscientists working in these areas will readily subscribe

Thomas Szanto

thomas.szanto@hum.ku.dk

Joel Krueger

j.krueger@exeter.ac.uk

1 Department of Media, Cognition and Communication, University of Copenhagen, Karen Blixens Plads 8, 2300 Copenhagen S, Denmark

2 Sociology, Philosophy, and Anthropology, University of Exeter, Amory Building, Rennes Drive, Exeter EX4 4RJ, UK at least to the general contours of this picture. It is all the more surprising, therefore, that little attention has so far been paid to conceptually and systematically clarifying how these different social processes might intersect and impact one another. Instead, most of the relevant philosophical, socialscientific, and empirical work in the past decade has focused primarily on specific aspects of these different dimensions of sociality in isolation, and has not systematically addressed their interconnection.

This special issue shifts the focus of these debates by exploring links between philosophical and psychological research on empathy, shared emotions, and social identity. The individual contributions to this special issue are diverse and cover a range of topics and issues. They cluster around the following sets of questions:

i. What psychological mechanisms underpin instrumental helping and prosocial behaviour?

ii. To what extent does empathy enable joint agency, emotional sharing, and the emergence and maintenance of group and social identity? What role do pre-reflective or subpersonal process play here? What about narrative practices?

iii. Conversely, how do shared emotions, social identity, or group membership modulate or bias empathic understanding at both the interpersonal and the intergroup level?

iv. What is the nature of social identification, and how does our ability to empathize with a particular other impact our identification with a group?

v. Do complex forms of social identification (e.g., groupidentification) presuppose more basic forms of empathy or other interpersonal processes like joint attention and imitation? What exclusionary and ingroup/ outgroup mechanisms are involved?

vi. What role do the interrelated socio-psychological processes of stereotyping, social (self-)categorization, depersonalization, or dehumanization play here, and how does self-alienation factor in? 
Before we outline how the nine contributions to this issue address these questions, we will first provide context by sketching the most relevant recent debates at the intersection between social cognition, social ontology, and social psychology. Along the way, we shall point to some unresolved issues, desiderata, and avenues for future research.

\section{Research Background and Future Avenues}

Consider first recent work on social cognition in philosophy and the cognitive sciences, where we can witness a partial shift of focus away from the more established theory of mind debate to explorations of the relation between empathy and affective sharing. One of the central questions in this area of research is whether empathy amounts to some form of affective sharing - that is, whether the sharing of affective states between the subject and the target of empathy is a necessary requirement for (successful) empathic understanding (cf. Michael 2014). According to one trend in current social cognition research, which is gaining increased traction, empathy is conceived in primarily affective terms, rather than as a predominantly cognitive form perspectivetaking or mindreading. ${ }^{1}$ Here, empathy is characterized as the "simulation of the feelings of others" or as "caused by sharing the emotions of another person" (Hein and Singer 2008; cf. de Vignemont and Singer 2006). Relatedly, it has been argued that empathy is itself an affective state, which necessarily requires "interpersonal similarity": some relevant similarity between the affective state of the subject and the target of empathy (Jacob 2011; De Vignemont and Jacob 2012). Moreover, according to this view, empathy also entails a "care" for the affective state of the other, which brings it closer to what is usually called sympathy (ibid.) (although none of these authors hold that empathy thereby can be equated with sympathy).

Meanwhile, authors mainly drawing on the phenomenological tradition, and especially on the work of Edmund Husserl, Edith Stein, Max Scheler or Alfred Schütz, have forcefully challenged this assumption. They claim that empathy-viewed in this tradition roughly as a sui generis ability to perceptually access and understand the experiential life of others (Zahavi 2014; Jardine and Szanto 2017; Krueger 2018; cf. also Michael and Fardo 2014) —is neither itself an affective state nor requires any isomorphism between subjects' and the targets' mental or affective states. Empathy does not amount to any form of affective sharing of the relevant states, either. As phenomenologists such as Scheler (1913/1926) or Stein $(1917,1922)$ have long

${ }^{1}$ E.g., Gallese (2001), Decety and Lamm (2006), Decety and Meyer (2008), Eisenberg and Eggum (2009), cf. de Vignemont (2009). emphasized, it must be markedly distinguished not only from emotional contagion and forms of 'feeling-with' (as in 'I feel with your loss'), or sympathy, but also from any form of 'feeling-together' ${ }^{2}$ or forms of emotional sharing that today are discussed in terms collective emotions. ${ }^{3}$

Debates about collective emotions concern whether and in what sense a collection of individuals can properly speaking share an emotional episode. Consider, for example, members of a football team who are collectively (i.e., jointly, as a team) grieving over their deceased teammate, or who are proud of their success in the tournament (' $W e$ are very happy with the result').

But apart from the phenomenological accounts mentioned previously, there is very little conceptual precision when it comes to determining the relation between empathy and both interpersonal and collective forms of emotional sharing. Incidentally, this relation has hardly been empirically studied either, and is yet very little understood. However one may decide upon this issue - and the editors, as well as most contributors to this issue, tend to side with the phenomenological line of thought-for the present context it is crucial to note the following. Even if one holds that empathy and emotional sharing are in fact clearly distinct social processes - and that, moreover, the former doesn't necessarily involve the latter - one can still consistently hold that they are interlinked by various social-psychological dynamics.

In this connection, it's worth mentioning a bold phenomenologically inspired proposal by Salice and Taipale (2015) that aims to bridge social cognition and social ontology by developing an original account of group-directed empathy. The authors suggest that it is possible to have an empathic act when the target is not an individual or even individual members of a group, but rather the group itself. This possibility, together with the phenomenological insight that empathy is only possible if the empathic target has a (directly) perceptible body, leads them to the conclusion that groups as such are embodied agents; they may properly be attributed a body of their own, i.e., one that is not reducible to the bodies of their individual members. What is more, in discussing the differences between individual- and group-directed empathy,

\footnotetext{
2 See Zahavi (2014, 2015a, 2018), León and Zahavi (2016), Szanto (2015), Szanto and Moran (2015, 2016); cf. also Vendrell Ferran (2015), Svenaeus $(2016,2018)$.

${ }^{3}$ Research on shared or collective emotions is still very recent, but constitutes an already burgeoning interdisciplinary field, including sociologists, social and developmental psychologists (cf., for an overview, von Scheve and Salmela 2014) and numerous philosophers (e.g., Gilbert 2002, 2014; Tollefsen 2006; Konzelmann Ziv 2007, 2009; Helm 2008, 2017; Schmid 2009, 2014; Huebner 2011; Michael 2011; Salmela 2012, 2014; Salmela and Nagatsu 2016a, 2016b; Krueger 2014, 2015; Szanto 2015, 2018; León et al. (forthcoming); Thonhauser forthcoming; for recent review articles, see Schmid (2018) and Salmela (forthcoming).
} 
and in particular different display and vehicles of the expression of (shared) emotions, they argue that for structural and essential reasons our empathic grasp of the affective states of groups is more informative, "more extensive, exhaustive", and indeed "more adequate", than in the case of individuals (ibid., p. 166). Similarly, one of us (Szanto 2015) has claimed that individual-member-to-group and groupto-individual-member directed empathy might correct for various cases of misidentification regarding shared emotions (even if they are, pace Salice and Taipale, not more reliable or adequate than ordinary interpersonal forms). Such misidentifications include, among others, misidentification what the communities' standards of emotional sharing are, or whether there are any properly shared emotions between a given member and the group in the first place.

A number of issues, however, remained unresolved with regard to such collective forms of empathy. For example, what is the relation between such collective empathic stances and feelings of group-belongingness, ingroup homogeneity, or favoritism? Presumably, if a group collectively engages in empathy towards outgroups, this will strengthen ingroup cohesion, for instance, by way of social distinction. Furthermore, if individual members empathize with the shared emotions of their ingroup, they may gain additional affective reasons to retain their membership. For example, a member of a political movement may thus learn that certain values or affective concerns are shared by other members, a fact that she might not have realized simply by focusing on some doctrinal propositions of the movement; and this will typically reinforce her attachment. Identifying the norms guiding emotional sharing via group-directed empathy may also facilitate affective conformity, and help maintain the shared emotional patterns of the given group. Finally, groupdirected empathy may reinforce a sense of belonging, if, for instance, individuals become aware that they are not empathized with as individuals, but become targets of empathic stances of other groups or third parties, as members of a certain group. This seems especially salient in settings of intergroup antagonism, such as racism, when social cognition towards (and indeed recognition of) one's own ingroup is biased or disrupted (cf. Ito and Bartholow 2009; Xu et al. 2009; Losin et al. 2012). Even though there has been some related empirical research on the modulatory effects of sociocultural identity and ingroup/outgroup distinctions on interpersonal empathic encounters (see more below), such effects on group-directed or intergroup empathic relations have so far been underexamined.

Another relevant context where the connection between mindreading, simulation, and empathy, on one hand, and forms of collaboration, on the other, has been systematically investigated is the enactivist and so-called "interactionist" paradigm in social cognition research. Different proposals have investigated in what sense social cognition can be viewed as a specific form of (embodied) interaction. From this enactive perspective, the claim is not simply that face-to-face interaction is a contextual factor or an enabling condition for social cognition but rather that is it a constitutive feature of it. ${ }^{4}$ Furthermore, there is a related and rapidly increasing body of work exploring, more specifically, links not just between social cognition and interaction but also between social cognition and joint attention and joint agency. ${ }^{5}$ For instance, it has not only been argued that collaborating agents are better mindreaders, since they can draw on a situational cues afforded by the very interaction, which might be otherwise unavailable (Butterfill 2013) ${ }^{6}$; moreover, classical and contemporary phenomenologists have suggested that more complex forms of experiential we-intentionality and group agency must in fact be founded upon more basic, embodied forms of interaction and, in particular, face-to-face empathic encounters (Zahavi 2014, 2015a, b; León and Zahavi 2016; cf. also Szanto 2015, 2018).

Two further topics regarding the relation between interpersonal empathic stances and the broader social and moral context in which they are embedded should be flagged here. The first concerns the role of social typification, an issue that has not been sufficiently recognized in contemporary discussions in social cognition, but that has been explored in great detail in the work of early phenomenological thinkers such as Schütz and Gurwitsch. As they argue, in all interpersonal empathic encounters there is always a more or less explicit and more or less specific typification of the other(s) at play. Others are grasped and recognized as concrete personal individuals in direct face-to-face encounters and, at the same time, as more or less "anonymous" representatives or proxies of ideal social types (e.g., Schutz 1932; Schutz and Luckmann 1973; cf. Zahavi 2014 and esp. Taipale 2016). Moreover, concrete others are always and already given "as bearers of roles", and in more or less specific and more or less familiar social "situations" (Gurwitsch 1931, p. 111). Again, others never simply appear in a social void. For instance, when greeting the postman who just handed you a letter, you directly perceive both the charming young man and the anonymous one whom you were eagerly awaiting this morning, and maybe even the surprisingly cheerful

\footnotetext{
${ }^{4}$ Cf. De Jaegher and Di Paolo (2007), De Jaegher et al. (2010), Fuchs and De Jaegher (2009), Gallagher (2008a, b), Gallagher and Varga (2014), Krueger (2011, 2012), Schilbach et al. (2013), Satne and Roepstorff (2015), Chemero (2016), see, critically; Herschbach (2012), Michael et al. (2014), Overgaard and Michael (2015).

5 E.g., Pacherie and Dokic (2006), Hobson and Hobson (2007), Gallotti and Frith (2013), Tomasello (2014), Abramova and Slors (2015), Bianchin (2015), León (2016), Martens and Schlicht (2018).

${ }^{6}$ Incidentally, early phenomenologists such as Gurwitsch (1931) have already pursued very similar lines of interactionist argument regarding empathy, see Jardine and Szanto (2017), and more below.
} 
representative of the near-bankrupt state-service that is known for how poorly their employees are paid. Current approaches typically don't pay enough attention to this interplay between social and situational typification, direct perception and empathy.

The second issue concerns the relation between empathy and certain morally relevant stances towards the other, in particular, forms of recognition, social visibility, and respect. For example, it has been argued that early phenomenological conceptions of empathy such as Stein's and Husserl's have the resources to clarify the moral and epistemological foundations of recognition. Specifically, they can help to refine notions like the "elementary recognition" of the personhood of others, introduced by critical theorist such as Honneth (2001), and understood as a process that precedes objectifying judgment or explicit evaluative appraisal of specific characteristics of the other (Jardine 2015, 2017; cf. also Varga and Gallagher 2011). At the same time, as Jardine $(2015,2017)$ suggests, the nuanced direct perceptual account of empathy that we find for example in Stein's work may help clarifying the related issue of "social (in)visibility" of others (Honneth 2001). For, such a phenomenological account could specify the interpersonal, affective, and practical contexts in which empathic recognition of others is always embedded, and also account for the empathic grasp of the more complex motivational and rational relations between another's mental and affective states. Furthermore, as Drummond (2006) has elaborated, moral responses to others, and in particular, respect, are rooted in empathy, as only the latter provides the means to recognize the radical otherness of the other-a prerequisite for respect for another person as such. Such "recognition respect" (Darwall 2006) contrasts with sympathetic affective processes (notably sympathy and compassion), which are rooted not in the other's otherness, but rather in their sameness or similarity, and the possibility of persons to communalize an share emotional states or values. (On recognition and empathy, see also Fuchs' and Zahavi's contributions to this issue).

Finally, turning to empirical research, we find a vast body of evidence that emotional sharing and social identification not only motivates and modulates but indeed variously biases and disrupts empathic encounters. More specifically, neurophysiological data suggests that group and ethnic membership often biases the affective, cognitive, responsive or emotion-regulative components of empathy (for a review, see Eres and Molenberghs 2013). For example, it has been shown that empathic and vicarious sensory responses (e.g., vicarious pain) are more likely to be elicited in ingroup than outgroup members (e.g., in ethnic, racial or political conflict settings). ${ }^{7}$ Similarly, it has been shown that

\footnotetext{
7 See Xu et al. (2009), Avenanti et al. (2010), Chiao and Mathur (2010), Hein et al. (2010), Beeney et al. (2011), Cikara et al. (2011),
}

the underlying neurophysiological mechanisms of empathy, such as neural activation in mental simulation, is reduced by outgroup prejudices, ingroup favoritism, and sociocultural or ethnic identity in general, but also in certain professional (e.g., medical) contexts (Cheng et al. 2007; Decety et al. 2010). Furthermore, analyzing collective rituals (e.g., firewalking spectacles) it has been observed that there is a tight synchronization of cardiovascular arousal patterns between performers and family-members in the audience, which are similar to affective mirroring processes underlying empathy (Konvalinka et al. 2011). Social identity related modulations have also been demonstrated regarding the accuracy of perception and prediction of group-level emotions from outgroups (Seger et al. 2009). Such biases have even been observed in early-infant imitation (Buttelmann et al. 2013; Over and Carpenter 2012, 2013) and learning (Kinzler et al. 2011), suggesting that mental simulation or affective mirroring is reduced by outgroup prejudices already at an early phase of personal development (4-5 years of age) (cf. Buttelmann and Böhm 2014).

It is not quite clear whether and how these social perception biases challenge or even undermine the baseline phenomenological picture of empathy, according to which empathy is—primarily, at least—based on direct perception of embodied minds or direct embodied interaction. It is not even clear whether further empirical research could possibly settle this issue, or whether we need more conceptual and phenomenologically grounded studies. Gallagher and Varga (2014), who have endorsed the latter strategy, convincingly argue that far from challenging the idea of direct embodied perception, these findings rather undermine the deeply entrenched view from mainstream social cognition research, according to which there would be some hardwired theory of mind modules.

In a related field of social-psychological research, a number of features regarding group size, structure and ingroup/ outgroup dynamics have been studied, in order to investigate how they modulate prosocial responses and, in particular, on the attribution and perception of mental and affective properties, or the "humanness", of others. Research on the familiar phenomenon of "collapse of compassion" has examined why groups in need are less prone to elicit empathic concern than individuals. Moreover, it has been shown that the increase of the number of suffering individuals, and in particular of outgroup members, decreases prosocial affective responses and behaviour (Cameron and Payne 2011). There has been also research on how and which types of group membership diminish the attribution of mental states

Footnote 7 (continued)

Azevedo et al. (2013), Bruneau et al. (2012), Gutsell and Inzlicht (2012); cf. Gallagher and Varga (2014). 
and emotions to individuals. It has been demonstrated that there are higher thresholds for attributing and perceiving minds in outgroup than ingroup faces-they require for example more salient anthropomorphic characteristics or stronger emotional expressions (Hackel et al. 2014; cf. also Epley et al. 2007). These effects have been even confirmed in the so-called "minimal group" condition, where the paradigm includes randomized group settings. Thus, even without any relevant prior experiences of intergroup conflicts and the absence of relevant stereotypes, subjects are prone to such social perception biases (Hackel et al. 2014). Related studies have focused on the modulation in mind attribution and perception and the issue of "group entitativity" (Campbell 1958; Hamilton and Sherman 1996; Lickel et al. 2000). The entitativity of a group refers to the degree according to which a collection of individuals is subjectively perceived precisely not as a random collection or aggregate but as a coherent social unit. It has been demonstrated that there is a strong negative correlation between the attribution of minds and the degree of group entitativity: subjects tend to attribute less autonomy and less "humanness" features, such as own mental states, intentions, etc., to individuals who are perceived as belonging to highly entitative groups (e.g., tight-knit, homogenous communities) (Morewedge et al. 2013). All these depersonalization and infra-humanization effects are consistently heightened by strong ingroup identification of social cognizers. On the other hand, the effects are moderated by (perceived or real) specific threats from outgroup members, which then facilitates mind attribution and the accuracy of social perception. This latter effect seems particularly interesting in political, ethnic or other intergroup conflicts.

Again, neither mainstream work in social cognition research, which till very recently focused mostly on the theory of mind debate and developmental-psychological issues related to it, nor phenomenological, interactionist or direct perception accounts of empathy have so far seriously engaged with these empirical studies. ${ }^{8}$ This oversight represents a significant lacuna, all the more so as a systematic investigation of these and related ${ }^{9}$ social perception biases

\footnotetext{
${ }^{8}$ For the only exceptions we are aware of, see again Gallagher and Varga (2014), Varga (2017), and Fuchs's contribution to this issue.

${ }^{9}$ One such related family of social cognition biases comprises recent discussions of so-called 'implicit' (mostly racial or gender-related) biases. While psychologists and cognitive scientists have extensively investigated the underlying processes of implicit social cognition (cf. for reviews, see Greenwald and Banaji 1995; Frith and Frith 2008; Nosek et al. 2011), and philosophers have begun to systematically tackle the epistemology, metaphysics and ethics of implicit biases (Brownstein and Saul 2016a, b; for review articles see: Kelly and Roedder 2008; Brownstein 2015; Holroyd et al. 2017), philosophical, and in particular phenomenological, research on the relationship between social perception, embodiment and empathy on the one hand, and implicit biases on the other is missing.
}

might offer new avenues to also conceptually investigate the still little understood relationship between empathy, sharedness and group membership.

\section{The Papers of the Issue}

The papers in this special issue can be divided into three main groups: (1) The first consists of two papers discussing the relationship between empathy, cooperation and prosocial behaviour. (2) The three papers of the second group tackle interpersonal and collective forms of sharing, while (3) the four last papers address the complex, often biased or deviant relationship, between empathy, social and group identification, and the constitution of a 'we'. Let us now give brief synopses of each of these contributions.

Anika Fiebich's "Social Cognition, Empathy and AgentSpecificities in Cooperation" begins this special issue by offering a rich three-dimensional characterization of cooperation. Fiebich argues that cooperative behavior lies on continuum of cognitive, behavioral, and affective dimensions, all of which must be accounted for if we are to understand how it is that we successfully do things together. According to Fiebich, current debates about cooperation and joint actions-i.e., actions where two or more social agents share an intention to work together toward a common goal, such as moving a piece of furniture or playing music — are generally framed in folk psychological term. In other words, dominant accounts (e.g., Bratman, Searle) portray joints actions as requiring sophisticated theory of mind capacities that enable individuals to accurately represent the desires and intentions of others in order to integrate these with the individual's own desires and intentions. Drawing on both developmental and phenomenological research, Fiebich challenges this cognitivist picture. She summons different streams of empirical evidence to argue that children engage in many forms of affectively-guided cooperative activities long before they acquire the metacognitive capacities needed for a theory of mind. And she concludes with a call for a plural approach to cooperation, one which acknowledges the ways that shared affective states and agent-specificities can both supplement and, at times, replace, metacognitive capacities in the realm of cooperative behavior.

John Michael and Marcell Székely's "Goal Slippage: A Mechanism for Spontaneous Instrumental Helping in Infancy" continues this developmental focus. They note that developmental psychology has, in recent years, shown increased interest in various forms of prosocial behavior in infants and young children: e.g., comforting, sharing, pointing to provide information, and spontaneous instrumental helping (e.g., helping to retrieve a puzzle piece that's fallen on the floor, or putting a stack of books back into a cabinet). This ability to spontaneously and flexibly adapt 
to the intentions and behavior of others, and to integrate our own behavioral responses with theirs, is at the root of our cooperative capacities. Michael and Székely critically evaluate several models that attempt to explain the psychological mechanisms underpinning this ability, highlighting strengths and weaknesses of each. They then propose their own model-the "goal slippage" model of spontaneous instrumental helping-based on the core idea that the identification of an agent's goal leads infants to take up that goal as though it were their own, since infants lack the internal resources to quarantine others' goals from their own endogenously generated goals. Michael and Székely develop their view by clarifying the psychological content of others' goals the infant takes up as though they were her own by developing a "lean" notion of content. They then argue that their goal slippage model is better suited for explaining cognitively undemanding forms of prosocial behavior than other competing models, and they show how it might provide a useful starting point for further research into the ontogeny of the psychological underpinnings of human cooperation.

Anna Ciaunica's "The 'Meeting of Bodies': Empathy and Basic Forms of Shared Experiences" shifts the focus from shared behavior to shared experiences. Ciaunica begins with a seemingly obvious observation that has nevertheless been overlooked in ongoing discussions of empathy and embodiment: we begin our social life within the lived body of another, i.e., our mother. She argues that this observation has explanatory significance for debates about both the development and character of our empathic capacities. This is because most current discussions of empathy, including those drawing upon phenomenologists like Husserl, Sartre, Stein, Scheler, and Schutz, focus primarily on face-to-face encounters in which we see others' mental states embodied in their expressive and goal-directed behavior. According to these vision-centric approaches, we share others' experiences insofar as they become perceptual content for our own experience. Ciaunica does not dispute the importance of these phenomenologically motivated accounts. However, she argues that before we visually relate to other subjects as objects, we are already bodily connected with themas becomes clear when we look at the various ways that we are bodily and experientially bound up with caregivers during pregnancy and early infancy. Citing developmental evidence, Ciaunica argues that these "skin-to-skin" encounters do not disappear following infancy, but rather remain integral to our empathic encounters with others throughout our life. Accordingly, our models of empathy and experiential sharing should begin with a consideration of how these proximal body-based ways of establishing mutual awareness underwrite the visuo-spatial forms of empathy that are often thought to be developmentally primitive.

Alessandro Salice, Simon Høffding, and Shaun Gallagher's "Putting Plural Self-Awareness into Practice: The
Phenomenology of Expert Musicianship" is, like Ciaunica's contribution, a focused investigation of the character of shared experience. However, whereas Ciaunica focuses on shared experience during pregnancy and early infancy, these authors have a different target: the phenomenology of shared agency when performing music together. They take a careful look at qualitative data drawn from interviews with highly-skilled musicians, The Danish String Quartet; these interviews lend insight into what it's like to perform music with others at a world-class level of expertise. Based on these interviews, Salice, Høffding, and Gallagher argue that, within this performing experience, the musicians develop a sense of "we-agency": the experience of performing a single action toward which the individual members enjoy an epistemically privileged access. This "we-agency" involves more than mere motor resonance between the performers or explicit coordination arising from members paying attention to what the others are doing. There is, additionally, an affective, interkinesthetic awareness that one's individual sense of agency has been drawn up into a group agency-a "we-agency"-in which one's perception-action loops are responsive to, and modulate by, those of the other members. The authors conclude their rich phenomenological analysis by discussing the significance of this view for thinking about the place of self-knowledge and observational knowledge in collective action.

Shaun Gallagher and Deborah Tollefsen's “Advancing the 'We' Through Narrative" puts narrativity to center stage in the collective intentionality debate. To be sure, it is fairly uncontroversial that narratives play an important role not only in the framing and maintaining, or indeed the establishment of personal identity, but also for collective "we-identities". Yet, the concept of narrativity has so far been rather sidelined in social ontology. This is all the more surprising given the veritable research industry on the cognate notion of collective memory, and if we consider that narrativity has also been increasingly discussed in the philosophy of personal identity and the philosophy of emotions in the past decades. In the face of this, Gallagher and Tollefsen propose a new account of so-called "we-narratives". Following the authors, we-narratives can roughly be characterized as joint communicative reflections or stories about a group's past, present or future actions, intentions, goals or norms. They are typically, though not necessarily, told or expressed in some discursive form from the first-person plural perspective ('what we were doing', 'what we ought to do next', etc.) (cf. also Tollefsen and Gallagher 2017). The authors consider a number of different, more or less ephemeral forms of joint agency and collective experiences (ad hoc, planned, and longer-term, coordinated joint actions), and show how we-narratives not only reflect the structure of the respective dyads or groups and build the typical representation format for a retrospective attribution of shared intentionality and 
agency; they also argue that we-narratives indeed underpin prospective joint intention formation and practical deliberation. Moreover, Gallagher and Tollefsen demonstrate how we-narratives play key roles in the formation of a robust group identity and thus contribute to groups' stability over time, beyond discrete collective actions and experiences and across changing individual membership.

Joona Taipale's "The Structure of Group Identification" presents a comprehensive and original account of group identification. For several decades now, the notion of group identification has been ubiquitous in developmental and social psychology. It has been extensively discussed to elaborate the nature of the affective, psychological and social-ontological relationship between individuals and groups. Curiously, however, a precise conceptual and phenomenological determination of the intentional and experiential structure of the identification at stake is still outstanding. Moreover, the notion is beset by a roaster of conceptual ambiguities, in particular when it comes to the nature of the target and the intentional act of identification. Taipale aims at disambiguating this notion, in order to demarcate it from cognate but different phenomena such as empathy, sympathy, and other relations of identity and similarity. Thus, the paper aims to advance our phenomenological understanding of the very act of identification. Taipale investigates a number or complex and important questions like: are there any relevant experiential, intentional, and structural differences between identifying with particular individuals, others qua group-members, and group as such? What is the nature of the experiential relation that identification with somebody entails for the subject and the target of identification, and what roles (if any) do identity and similarity play here? And is group identification a diachronically enfolding process of establishing a group membership, or is it the realization of an identity or similarity that has already been established? In tackling these fundamental issues, Taipale proposes a finegrained, multi-dimensional model of group identification, one which can account for different types of establishing and robustly maintaining the social identity of the subjects of identification, depending on the type and nature of their targets. ${ }^{10}$

Casey Rebecca Johnson's "Intellectual Humility and Empathy by Analogy" addresses the question of how imaginative perspective-taking is possible in cases of interpersonal encounters in which the other person is fundamentally different from or deeply disagreeing with oneself? After all, empathic understanding is crucial precisely when our empathetic target's intellectual outlook and/or experiential

\footnotetext{
${ }^{10}$ For a recent discussion of the relation between group identification and collective intentionality, pertinent to the present special issue, see Salice and Miyazono (forthcoming).
}

background starkly differ from our own. But some have recently denied that true interpersonal understanding is possible in such cases. In contrast, Johnson argues that defenders of a specific analogical conception of empathy need not recoil in the face of this challenge. Johnson addresses the challenge by bringing the relevant analogical account of empathy into relief against competing accounts, and in particular by drawing on the notion of intellectual humility, discussed in recent philosophical and psychological work. Once we recognize our own epistemic, cognitive and experiential limitations and realize that they are analogous to our empathetic targets, that is, once we exercise intellectual humility, Johnson argues, the way for empathy is paved, even if the barriers of understanding seem initially insurmountable.

Thomas Fuchs' paper "Empathy, Group Identity, and the Mechanisms of Exclusion: An Investigation into the Limits of Empathy" brings together the issue of group identification with the bounds of interpersonal understanding in the face of potentially insurmountable sociocultural or ethnic barriers. Like Johnson, Fuchs, too, fathoms the limits of empathy, but this time by drawing on historical examples of mass atrocities and genocides, and by discussing the phenomenon of a dissociation of empathy. What is the link between the empirically well-documented tendency to exhibit preferential biases in empathizing with one's ingroup (see above, Sect. 1) to the notorious Nazi perpetrator who, in empathic dissociation, behaves as a fully empathic family member while committing horrific mass executions in concentration camps? Fortunately, there seems to be no direct or short route leading from the former to the latter. However, as Fuchs demonstrates, the two phenomena lie on the same spectrum of empathic bias. In exploring this tendency, Fuchs discusses different forms of empathy and the mutual interconnection between higher-level forms of empathy and recognition. He argues that the mere capacity of empathy is not sufficient to instantiate empathic stances towards all members of the human species. We need, additionally, a basic form of recognition of others as persons to whose claim we have to respond. Such recognition can then serve as a means of "extending" empathy, regardless of whether the empathic targets belong to one's ingroup or not. By investigating exclusionary and discriminatory mechanisms, and in particular dehumanization, and their impact on neutralizing empathic recognition, Fuchs ultimately argues that extreme dissociations of empathy have also detrimental top-down impact on primary empathy and the very personhood of the perpetrators, who eventually become themselves dehumanized.

Dan Zahavi's contribution "Empathy, Self-Alienation, and Group Membership" integrates a number of threads of the preceding articles. Zahavi engages in a phenomenological discussion of the ways in which second-personal encounters and empathic stances affect our self-understanding, and 
how their interconnection plays out in the constitution of plural, or 'we'-identities. Zahavi first sketches the conceptual terrain by critically comparing Heidegger's skeptical and deflationary views on empathy's role for the constitution and understanding of plural identities with other classical phenomenologists, who hold that dyadic-empathic engagements are indeed constitutive of the 'we'. Drawing chiefly on Husserl's theory of intersubjectivity and his theory of collective intentionality avant la lettre, but also critically discussing a number of contemporary accounts from philosophy, social and developmental psychology, Zahavi then explores the phenomenological, psychological and intersubjective mechanisms of this constitution, such as reciprocity, recognition, and self-alienation. He argues that they play a fundamental role for the establishment of a first-person plural perspective. Thus, by showing how shared and collective identities, or the 'we', require specific forms of self/otherrelations, involving specific forms of self-experience and self-alienation, Zahavi demonstrates how the first-person (I) and the second-person singular (I/Thou) and the first-person plural perspective (We) are essentially interlinked.

It is our hope that the articles in this special issue will spur further conversations about the underexamined links between empathy, shared emotions, and social identity.

Acknowledgements The guest editors of this special issue are very grateful for the thorough work of a number of experts who have kindly accepted to serve as anonymous referees for the contributions. We would also like to thank the editor-in-chief of Topoi, Fabio Paglieri, for an exceptionally smooth collaboration, his patience, and his willingness to host this issue. Thomas Szanto also wishes to acknowledge generous funding from his European Union (EU) Horizon-2020 Marie Skłodowska-Curie Individual Fellowships Grant SHARE (655067): "Shared Emotions, Group Membership, and Empathy", as well as from the Academy of Finland research project "Marginalization and Experience: Phenomenological Analyses of Normality and Abnormality" (MEPA).

\section{References}

Abramova E, Slors M (2015) Social cognition in simple action coordination: a case for direct perception. Conscious Cogn 36:519-531

Avenanti A, Angela S, Aglioti SM (2010) Racial bias reduces empathic sensorimotor resonance with other-race pain. Curr Biol 20(11):1018-1022

Azevedo RT, Macaluso E, Avenanti A, Santangelo V, Cazzato V, Aglioti SM (2013) Their pain is not our pain: brain and autonomic correlates of empathic resonance with the pain of same and different race individuals. Hum Brain Mapp 34(12):3168-3181

Beeney JE, Franklin RG Jr, Levy KN, Adams Jr RB (2011) I feel your pain: emotional closeness modulates neural responses to empathically experienced rejection. Soc Neurosci 6(4):369-376

Bianchin M (2015) Simulation and the we-mode. A cognitive account of plural first Persons. Philos Soc Sci 45(4-5):442-461

Brownstein M (2015) Implicit bias. The Stanford encyclopedia of philosophy. https://plato.stanford.edu/archives/spr2017/entries/ implicit-bias/
Brownstein M, Saul J (2016a) Implicit bias and philosophy. Volume 1: Metaphysics and epistemology. Oxford University Press, Oxford

Brownstein M, Saul J (2016b) Implicit bias and philosophy. Volume 2: Moral responsibility, structural injustice, and ethics. Oxford University Press, Oxford

Bruneau EG, Dufour N, Saxe R (2012) Social cognition in members of conflict groups: behavioural and neural responses in Arabs, Israelis and South Americans to each other's misfortunes. Philos Trans R Soc Lond B 367(1589):717-730

Buttelmann D, Böhm R (2014) The ontogeny of the motivation that underlies in-group bias. Psychol Sci 25(4):921-927

Buttelmann D, Zmyj N, Daum M, Carpenter M (2013) Selective imitation of in-group over out-group members in 14-month-old infants. Child Dev 84(2):422-428

Butterfill S (2013) Interacting mindreaders. Philos Stud 165(3):841-863

Cameron CD, Payne BK (2011) Escaping affect: how motivated emotion regulation creates insensitivity to mass suffering. J Pers Soc Psychol 100(1):1-15

Campbell DT (1958) Common fate, similarity, and other indices of the status of aggregates of persons as social entities. Behav Sci $3(1): 14-25$

Chemero A (2016) Sensorimotor empathy. J Conscious Stud 23(5-6):138-152

Cheng Y, Lin CP, Liu HL, Hsu YY, Lim KE, Hung D, Decety J (2007) Expertise modulates the perception of pain in others. Curr Biol 17(19):1708-1713

Chiao JY, Mathur VA (2010) Intergroup empathy: how does race affect empathic neural responses? Curr Biolog 20(11):478-480

Cikara M, Bruneau EG, Saxe RR (2011) Us and them: intergroup failures of empathy. Curr Dir Psychol Sci 20(3):149-153

Darwall SL (2006) The second-person standpoint: morality, respect, and accountability. Harvard University Press, Cambridge

De Vignemont F (2009) Drawing the boundary between low-level and high-level mindreading. Phil Stud 144(3):457-466

De Jaegher H, Di Paolo E (2007) Participatory sense-making. Phenomenol Cogn Sci 6(4):485-507

De Vignemont F, Jacob P (2012) What is it like to feel another's pain? Philos Sci 79(2):295-316

De Vignemont F, Singer T (2006) The empathic brain: how, when and why? Trend Cogn Sci 10(10):435-441

De Jaegher H, Di Paolo E, Gallagher S (2010) Can social interaction constitute social cognition? Trend Cogn Sci 14(10):441-447

Decety J, Lamm C (2006) Human empathy through the lens of social neuroscience. Sci World J 6:1146-1163

Decety J, Meyer M (2008) From emotion resonance to empathic understanding: a social developmental neuroscience account. Dev Psychopathol 20(4):1053-1080

Decety J, Yang CY, Cheng Y (2010) Physicians down-regulate their pain empathy response: an event-related brain potential study. Neuroimage 50(4):1676-1682

Drummond JJ (2006) Respect as a moral emotion: a phenomenological approach. Husserl Stud 22(1):1-27

Eisenberg N, Eggum ND (2009) Empathic responding: sympathy and personal distress. In: Decety JE, Ickes WE (eds) The social neuroscience of empathy. MIT Press, Cambridge, pp 71-83

Epley N, Waytz A, Cacioppo JT (2007) On seeing human: a three-factor theory of anthropomorphism. Psychol Rev 114(4):864-886

Eres R, Molenberghs P (2013) The influence of group membership on the neural correlates involved in empathy. Front Hum Neurosci 7:Art 176

Frith CD, Frith U (2008) Implicit and explicit processes in social cognition. Neuron 60(3):503-510

Fuchs T, De Jaegher H (2009) Enactive intersubjectivity: participatory sense-making and mutual incorporation. Phenomenol Cogn Sci 8(4):465-486 
Gallagher S (2008a) Direct perception in the intersubjective context. Conscious Cogn 17(2):535-543

Gallagher S (2008b) Inference or interaction: social cognition without precursors. Philos Explor 11(3):163-174

Gallagher S, Varga S (2014) Social constraints on the direct perception of emotions and intentions. Topoi 33(1):185-199

Gallese V (2001) The 'shared manifold' hypothesis. From mirror neurons to empathy. J Conscious Stud 8(5-6):33-50

Gallotti M, Frith CD (2013) Social cognition in the we-mode. Trends Cogn Sci 17(4):160-165

Gilbert M (2002) Collective guilt and collective guilt feelings. J Ethics 6(2):115-143

Gilbert M (2014) How we feel: understanding everyday collective emotion ascription. In: von Scheve C, Salmela M (eds) Collective emotions. Oxford University Press, Oxford, pp 17-31

Greenwald AG, Banaji MR (1995) Implicit social cognition: attitudes, self-esteem, and stereotypes. Psycholog Rev 102(1):4-27

Gurwitsch A (1931) [1979]) Human encounters in the social world (trans: Kersten F). Duquesne University Press, Duquesne

Gutsell JN, Inzlicht M (2012) Intergroup differences in the sharing of emotive states: neural evidence of an empathy gap. Soc Cogn Affect Neurosci 7(5):596-603

Hackel LM, Looser CE, Van Bavel JJ (2014) Group membership alters the threshold for mind perception: the role of social identity, collective identification, and intergroup threat. J Exp Soc Psychol 52:15-23

Hamilton DL, Sherman SJ (1996) Perceiving persons and groups. Psychol Rev 103(2):336-355

Hein G, Singer T (2008) I feel how you feel but not always: the empathic brain and its modulation. Curr Opin Neurobiol 18(2):153-158

Hein G, Silani G, Preuschoff K, Batson CD, Singer T (2010) Neural responses to ingroup and outgroup members' suffering predict individual differences in costly helping. Neuron 68(1):149-160

Helm BW (2008) Plural agents. Noûs 42(1):17-49

Helm BW (2017) Communities of respect: grounding responsibility, authority, and dignity. Oxford University Press, Oxford

Herschbach M (2012) On the role of social interaction in social cognition: a mechanistic alternative to enactivism. Phenomenol Cogn Sci 11(4):467-486

Hobson JA, Hobson PR (2007) Identification: the missing link between joint attention and imitation? Dev Psychopathol 19(2):411-431

Holroyd J, Scaife R, Stafford T (2017) What is implicit bias? Philos Compass 12:12437. https://doi.org/10.1111/phc3.12437e.

Honneth A (2001) Recognition. Proc Aristot Soc Suppl Vol 75:111-126

Huebner B (2011) Genuinely collective emotions. Eur J Philos Sci 1(1):89-118

Ito TA, Bartholow BD (2009) The neural correlates of race. Trends Cogn Sci 13(12):524-531

Jacob P (2011) The direct-perception model of empathy: a critique. Rev Philos Psychol 2(3):519-540

Jardine J (2015) Stein and Honneth on empathy and emotional recognition. Hum Stud 38(4):567-589

Jardine J (2017) Elementary recognition and empathy: a Husserlian account. Metodo 5(1):143-170

Jardine J, Szanto T (2017) Empathy in the phenomenological tradition. In: HL, Maibom (eds) The Routledge handbook of philosophy of empathy. Routledge, London, pp 86-97

Kelly D, Roedder E (2008) Racial cognition and the ethics of implicit bias. Philos Compass 3(3):522-540

Kinzler KD, Corriveau KH, Harris PL (2011) Children's selective trust in native-accented speakers. Dev Sci 14(1):106-111

Konvalinka I, Xygalatas D, Bulbulia J, Schjødt U, Jegindø EM, Wallot S, Orden GV, Roepstorff A (2011) Synchronized arousal between performers and related spectators in a fire-walking ritual. Proc Natl Acad Sci USA 108(20):8514-8519
Konzelmann Ziv A (2007) Collective guilt feeling revisited. Dialectica 61(3):467-493

Konzelmann Ziv A (2009) The semantics of shared emotion. Univ Philos 26(52):81-106

Krueger J (2011) Extended cognition and the space of social interaction. Conscious Cogn 20(3):643-657

Krueger J (2012) Seeing mind in action. Phenomenol Cogn Sci 11(2):149-173

Krueger J (2014) Varieties of extended emotions. Phenomenol Cogn Sci 13(4):533-555

Krueger J (2015) The affective "we": self-regulation and shared emotions. In: Szanto T, Moran D (eds) Phenomenology of sociality: discovering the we. Routledge, New York, pp 263-277

Krueger J (2018) Direct social perception. In: Newen A, De Bruin D, Gallagher S (eds) The Oxford handbook of 4E cognition. Oxford University Press, Oxford, pp 301-320

León F (2016) An interactionist approach to shared cognition: some prospects and challenges. In: Szanto T, Moran D (eds) The phenomenology of sociality. Discovering the "We". Routledge, London

León F, Zahavi D (2016) Phenomenology of experiential sharing: the contribution of Schutz and Walther. In: Salice A, Schmid HB (eds) Social reality: the phenomenological approach. Springer, Dordrecht

León F, Szanto T, Zahavi D (forthcoming) Emotional sharing and the extended mind. Synthese. https://doi.org/10.1007/s1122 9-017-1351-x

Lickel B, Hamilton DL, Wieczorkowska G, Lewis A, Sherman SJ, Uhles AN (2000) Varieties of groups and the perception of group entitativity. J Personal Soc Psychol 78(2):223-246

Losin EAR, Iacoboni M, Martin A, Cross KA, Dapretto M (2012) Race modulates neural activity during imitation. Neuroimage 59(4):3594-3603

Martens J, Schlicht T (2018) Individualism versus interactionism about social understanding. Phenomenol Cogn Sci 17(2):245-266

Michael J (2011) Shared emotions and joint action. Rev Philos Psychol 2(2):355-373

Michael J (2014) Towards a consensus about the role of empathy in interpersonal understanding. Topoi 33(1):157-172

Michael J, Fardo F (2014) What (if anything) is shared in pain empathy? A critical discussion of De Vignemont and Jacobs's theory of the neural substrate of pain empathy. Philos Sci 81(1):154-160

Michael J, Christensen W, Overgaard S (2014) Mindreading as social expertise. Synthese 191(5):817-840

Morewedge CK, Chandler JJ, Smith R, Schwarz N, Schooler J (2013) Lost in the crowd: entitative group membership reduces mind attribution. Conscious Cogn 22(4):1195-1205

Nosek BA, Hawkins CB, Frazier RS (2011) Implicit social cognition: from measures to mechanisms. Trends Cogn Sci 15(4):152-159

Over H, Carpenter M (2012) Putting the social into social learning: explaining both selectivity and fidelity in children's copying behavior. J Comput Psychol 126(2):182-192

Over H, Carpenter M (2013) The social side of imitation. Child Dev Perspect 7(1):6-11

Overgaard S, Michael J (2015) The interactive turn in social cognition research: a critique. Philos Psychol 28(2):160-183

Pacherie E, Dokic J (2006) From mirror neurons to joint actions. Cogn Syst Res 7(2-3):101-112

Salice A, Miyazomno K (forthcoming) Being one of us. Group identification, joint actions, and collective intentionality. Philos Psychol

Salice A, Taipale J (2015) Empathizing with groups: a phenomenological account of group-directed empathy. J Phenomen Psychol 46:163-184

Salmela M (2012) Shared emotions. Philos Explor 15(1):33-46

Salmela M (2014) The functions of collective emotions in social groups. In: Konzelmann Ziv A, Schmid HB (eds) Institutions, 
emotions, and group agents. Contributions to social ontology. Springer, Dordrecht, pp 159-176

Salmela M (forthcoming) Can emotions be collective? In Scarantino A (ed) The Routledge handbook in emotion theory. London: Routledge

Salmela M, Nagatsu M (2016a) Collective emotions and joint action. J Soc Ontol 2(1):33-57

Salmela M, Nagatsu M (2016b) How does it really feel to act together? Shared emotions and the phenomenology of We-agency. Phenomenol Cogn Sci 16(3):449-470

Satne G, Roepstorff A (2015) Introduction: from interacting agents to engaging persons. J Consciousness Stud 22(1/2):9-23

Scheler M (1913/1926) [1954]. The nature of sympathy (trans: Heath P). Routledge \& Kegan Paul, London

Scheve C von, Salmela M (2014) Collective emotions. Oxford University Press, Oxford

Schilbach L, Timmermans B, Reddy V, Costall A, Bente G, Schlicht T, Vogeley K (2013) Toward a second-person neuroscience. Behav Brain Sci 36(4):393-414

Schmid HB (2009) Plural action. Essays in philosophy and social science. Springer, Dordrecht

Schmid HB (2014) The feeling of being a group. Corporate emotions and collective consciousness. In: von Scheve C, Salmela M (eds) Collective emotions. Oxford University Press, Oxford, pp 3-16

Schmid HB (2018) Collective emotions. In: Ludwig K, Jankovic M (eds) The Routledge handbook of collective intentionality. Routledge, London

Schutz A (1932[1967]) The phenomenology of the social world (Trans: Walsh G, Lehnert F). Northwestern University Press, Evanston

Schutz A, Luckmann T (1973) The structures of the life-world, vol 1, 2. (Trans: Zaner RM, Engelhardt HT). Northwestern University Press, Evanston

Seger CR, Smith ER, Kinias Z, Mackie DM (2009) Knowing how they feel: Perceiving emotions felt by outgroups. J Exp Soc Psychol 45(1):80-89

Stein E (1917) On the problem of empathy (trans: Stein W). ICS Publication 1989, Washington, DC

Stein E (1922) Philosophy of psychology and the humanities (trans: Baseheart MC, Sawicki M). ICS Publication 2000, Washington, DC

Svenaeus F (2016) The phenomenology of empathy: a Steinian emotional account. Phenomenol Cogn Sci 15(2):227-245

Svenaeus F (2018) Edith Stein's phenomenology of sensual and emotional empathy. Phenomenol Cogn Sci 17(4):741-760

Szanto T (2015) Collective emotions, normativity, and empathy: a Steinian account. Hum Stud 38(4):503-527
Szanto T (2018) The phenomenology of shared emotions: reassessing Gerda Walther. In: Luft S, Hagengruber R (eds) Women phenomenologists on social ontology. Springer, Dordrecht, pp 85-104

Szanto T, Moran D (2015) Empathy and collective intentionality: the social philosophy of Edith Stein. Hum Stud 38(4):445-461 (Special Issue)

Szanto T, Moran D (2016) The phenomenology of sociality. discovering the 'We'. Routledge, London

Taipale J (2016) From types to tokens. Empathy and typification. In: Szanto T, Moran D (eds) The phenomenology of sociality. Discovering the "We". Routledge, London, pp 143-158

Thonhauser G (forthcoming). Shared emotions: a Steinian proposal. Phenom Cogn Sci. https://doi.org/10.1007/s11097-018-9561-3

Tollefsen D (2006) The rationality of collective guilt. Midwest Stud Philos 30(1):222-239

Tollefsen D, Gallagher S (2017) We-narratives and the stability and depth of shared agency. Phil Soc Sci 47(2):95-110

Tomasello M (2014) A natural history of human thinking. Harvard University Press, Cambridge

Varga S (2017) The case for mind perception. Synthese 194(3):787-807

Varga S, Gallagher S (2011) Critical social philosophy, Honneth and the role of primary intersubjectivity. Europ J Soc Theory $15(2): 243-260$

Vendrell Ferran Í (2015) Empathy, emotional sharing and feelings in Stein's early work. Hum Stud 38(4):481-450

Xu X, Zuo X, Wang X, Han S (2009) Do you feel my pain? Racial group membership modulates empathic neural responses. J Neurosci 29(26):8525-8529

Zahavi D (2011) Empathy and direct social perception: a phenomenological proposal. Rev Philos Psychol 2(3):541-558

Zahavi D (2014) Self and other. Exploring subjectivity, empathy, and shame. Oxford University Press, Oxford

Zahavi D (2015a) You, me, and we. The sharing of emotional experiences. J Conscious Stud 22(1-2):84-101

Zahavi D (2015b) Self and other: from pure ego to co-constituted we. Cont Philos Rev 48(2):143-160

Zahavi D (2018) Intersubjectivity, sociality, community: the contributions of the early phenomenologists. In: Zahavi D (ed) The Oxford handbook of the history of phenomenology. Oxford University Press, Oxford, pp 734-752

Publisher's Note Springer Nature remains neutral with regard to jurisdictional claims in published maps and institutional affiliations. 